\title{
La seguridad nacional y la seguridad internacional: el vínculo indisoluble en México
}

Alberto Lozano Vázquez *

\section{Universidad del Mar ${ }^{* *}$}

... [I]n a globalizing and increasingly interconnected world people are becoming increasingly aware of how security dynamics in different parts of the world, and even in their local neighborhoods, are often intimately connected. The traditional domestic-international divide when talking about security is therefore increasingly breaking down.

Christopher S. Browning (2018).

Safety is never a permanent state of affairs... Bad things are coming. Davos Seaworth. Game of Thrones (Eastwatch, 2017).

\section{Resumen}

Cl presente trabajo tiene el objetivo de elaborar sobre la intrín-

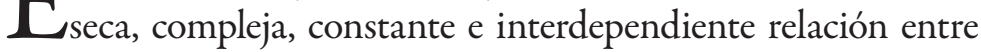
la seguridad nacional y la seguridad internacional. Aunque a esta relación ya se le ha nombrado de diversas maneras, se explica por qué la seguridad tiene como una importante característica a la dualidad que podemos representar analógicamente con el dios

\footnotetext{
* Es Doctor en Estudios Internacionales y Política Comparada por la Universidad de Miami (Estados Unidos). Actualmente es Profesor-Investigador de tiempo completo en la Universidad del Mar (UMAR), Campus Huatulco. Es miembro del Sistema Nacional de Investigadores del CONACyT (SNI-Nivel I) y Profesor con Perfil Deseable (PRODEP-SEP). Dirigió el Instituto de Estudios Internacionales Isidro Fabela de 2014 a 2020 en la UMAR; fue Presidente de la Asociación Mexicana de Estudios Internacionales (AMEI) de 2017 a 2019; y formó parte del Consejo Técnico del CENEVAL en EGEL-RI de 2014 a 2019. alozanov@huatulco.umar.mx. ORCID 0000-0002-6236-0728

** El autor agradece la asistencia de la Lic. Ilce Olivera Sánchez, del Centro de Documentación de Estudios Internacionales (CDEI) del Instituto Isidro Fabela, de la Universidad del Mar, y del Servicio Social de Silverio Aguilar Vázquez e Irma González García en la recopilación de información.
} 
Janus. Después repasa brevemente las nociones generales y tradicionales de seguridad nacional e internacional y finalmente analiza porqué algunas amenazas de la realidad mundial, que México ha padecido, no pueden entenderse ni explicarse sin la -a veces borrosa y desordenada- simultaneidad de ambos niveles. Las pandemias, el crimen transnacional organizado, la migración y la posible fusión entre terrorismo y crimen organizado son ejemplos que muestran lo complejo del vínculo entre la seguridad nacional y la internacional. El aporte consiste en recordar esta bi-dimensionalidad a los responsables de la seguridad de México que, aunque no es nueva, si es considerablemente vigente.

\section{Palabras clave}

Seguridad nacional, seguridad internacional, cara de Janus, México, estudios de seguridad, pandemias, crimen transnacional organizado, migración, terrorismo.

Fecha de recepción:

Mayo de 2020
Fecha de aceptación: junio de 2020

National security and international security: the indissoluble link in Mexico

Keywords

National security, international security, Janus face, Mexico, security studies, pandemics, transnational organized crime, migration, terrorism...

Final submission:

May 2020
Acceptance:

June 2020

\section{Abstract:}

This work has the goal of elaborating on the intrinsic, complex, constant and interdependent relationship between national security and international security. Although this relationship has been named already in different ways, it explains why security has as an important feature: to be a duality that we can represent analogically with the god Janus. Then it briefly reviews the general and traditional notions of national and 
international security and finally it analyzes why some threats of the world, which Mexico has suffered, cannot be understood or explained without the -sometimes messy and blurred-simultaneity of both levels. Pandemics, transnational organized crime, migration and the possible fusion between terrorism and organized crime are examples that show the complex nature of the link between national and international security. The contribution consists of remembering this bi-dimensionality to those responsible for the security of Mexico, which, although it is not new, is still in force.

\section{Introducción}

La seguridad nacional y la seguridad internacional están vinculadas indisolublemente; así es para México como para cualquier otro país, aunque esa vinculación suceda en intensidades diferenciadas dependiendo de la posición geoestratégica del país en cuestión y de la gravedad de las amenazas regionales. No hay un solo país libre de amenazas internas o externas. Por mucho que un Estado quiera aislarse, no puede evitar que lo que ocurre fuera de sus fronteras lo afecte, con distintas magnitudes y en diferentes áreas. De la misma manera que su desenvolvimiento interno tendrá efectos diversos en otros Estados, fuera de sus fronteras.

Las guerras internacionales, la degradación medioambiental, las crisis económicas, los regímenes internacionales contra el terrorismo o el narcotráfico, o las inestabilidades políticas (guerra civil, Estados fallidos o cualquier crisis de Estado) que ocurren internacionalmente se vinculan directa o indirectamente con la seguridad interna de México. Así ha sido históricamente y lo es actualmente. La academia y los tomadores de decisiones tendrán una visión frecuentemente más completa u holística si ubican, de cada fenómeno de inseguridad, su dimensión cruzada intra-nacional e inter-nacional.

Aquí exploraremos brevemente lo esencial de la seguridad nacional y la internacional, y trataremos de analizar porqué las pandemias, el crimen transnacional organizado, la migración y la posible fusión entre terrorismo y crimen organizado son casos difíciles de determinar en cuanto a su naturaleza nacional o interna- 
cional. Identificamos en medio de ambos niveles un centro turbio $y$ desordenado de la seguridad, en donde lo nacional y lo internacional parecen confusamente fusionarse, rebasando transnacionalmente nociones de territorio y soberanías. Hoy, la seguridad de los Estados está expuesta a factores internos, externos y mixtos.

\section{La seguridad tiene cara del dios Janus}

La seguridad es como la cara del dios romano Jano (en latín Janus): una dualidad. Esta analogía ${ }^{1}$ refleja la doble cara de la seguridad, la interna y la externa; la nacional y la internacional. Aunque puede haber un debate sobre la génesis de los peligros, parece que lo más sensato es aceptar que el origen y destino de las amenazas a la seguridad del Estado, de las personas o del medioambiente es bidireccional. Las amenazas a la seguridad regional, internacional o global pueden llegar desde el interior de un Estado cualquiera, de lugares muy particulares geo-localizados específicamente; o de manera inversa, las amenazas a nivel local provienen de procesos regionales o globales que se manifiestan con más énfasis en uno o más estados sin respetar las divisiones políticas determinadas por sus fronteras -a su vez definidas histórica y socialmente, no naturalmente-.

No hay un momento en el que los Estados, las personas o el medioambiente se encuentren absolutamente seguros, no existe un status de inseguridad nula; siempre hay circunstancias, condiciones y riegos latentes o manifiestos, internos o externos, que los pueden afectar natural, económica, política, jurídica, cultural y socialmente: calentamiento global y degradación medioambiental, escases de agua dulce, contaminación de atmósfera y océanos, migración urbana o rural forzada, pandemias, crisis económicas, corrupción, secuestro y extorsión virtual, crimen organizado, piratería en altamar, sobrepoblación, crisis alimentaria, desempleo

1 Basada a su vez en la analogía que hizo, entre muchos otros, la politóloga y socióloga Theda Skocpol (1979); para ella, los Estados tienen un doble anclaje, uno interno y uno externo ("The state, in short, is fundamentally Janus-faced...") Ver: Theda Skocpol, States and Social Revolutions. A Comparative Analysis of France, Russia and China, (Cambridge: Cambridge University Press, 1979). 
para las nuevas generaciones, terrorismo (y bioterrorismo), dictaduras, asesinatos en escuelas y centros comerciales, armas nucleares, guerrillas, o de plano hasta la caída de un nuevo asteroide que extinga a todo el mundo y especies conocidas como hace $66 \mathrm{mi}$ llones de años. Las amenazas a la seguridad de los Estados, de las personas o del medioambiente son incontables y pueden originarse dentro o fuera de los Estados-nación.

Esta reflexión sobre la dualidad en la seguridad aparentemente obvia, no lo es tanto al momento en que los gobiernos contemporaneos no toman en cuenta la variable internacional cuando planean y despliegan políticas públicas domésticas para garantizar la seguridad de su Estado -incluidos población y territorio-. Ante una nueva ola de nacionalismos a nivel internacional, donde sólo se privilegia lo interno, los responsables de los Estados -los estadistas- deben igualmente tener una doble visión -como el dios Janus- sobre el origen y naturaleza de las amenazas para mantener y garantizar la seguridad. Las fuerzas estructurales -incluidas las amenazas- que operan en la esfera internacional no pueden ser ignoradas, porque de lo contrario harán resentir su fuerza al interior de aquellos Estados que las ignoren. En los temas de inseguridad, lo interno y lo externo puede ser mutuamente constituyente. Las relaciones internacionales globalizadas y globalizantes muestran que lo doméstico y lo internacional puede estar clara o confusamente fusionado; ya no hay, en términos absolutos, un adentro y un afuera de las fronteras en la causalidad de las amenazas a la seguridad de los Estados, las personas o el medio ambiente. Por eso es que la seguridad, con todo y que es poliédrica, tiene dos caras respecto a las fronteras de los Estados que deben protegerla; es bifacial: la cara doméstica y la cara internacional, simultáneamente funcionales.

Esta analogía del dios Janus, que ubica y observa la seguridad en términos internos y externos, podría considerarse realista en el sentido de que su punto de partida es el Estado como objeto de referencia. El Janus de doble cara es el Estado; un Janus Leviatán. Pero si abrimos nuestro lente y ampliamos la visión, podríamos modificar la taxonomía conceptual y tomar como objeto de 
referencia a la seguridad de los humanos (la seguridad humana y no exclusivamente la seguridad estatal); entonces la doble visión de Janus tendría que ser local y global al mismo tiempo, Glocal: local por la ubicación específica del individuo respecto de cualquier amenaza, y global por el agregado de todos los individuos a nivel planetario bajo amenazas comunes, donde las fronteras tradicionales no tienen mucho sentido de ser. Lo local sigue siendo interno/doméstico y lo global sigue siendo externo. La analogía del dios Janus aún tiene sentido. Nos forzamos a entender los fenómenos de acuerdo a condiciones y consideraciones locales y globales, complementarias y simultáneas. ${ }^{2}$

\section{La seguridad nacional}

La seguridad nacional se refiere, principalmente, a la seguridad interior o doméstica. En la ortodoxia de los estudios de seguridad, la seguridad nacional es la más alta prioridad para cualquier Estado. La guerra -aconsejaba Maquiavelo- debía ser la única preocupación, meta y misión del príncipe: ahí radicaba su moral, en proteger a su Estado a partir de la capacidad de ejercer la violencia legitimada. La moral entonces de los estadistas no es la misma que la moral en los individuos. La conservación del Estado-nación requiere de todos los medios para protegerlo de todo y por encima de todo. Aquí el Estado mantiene una íntima relación con la violencia, el poder y la dominación -visible la influencia de Max Weber-, centrales para el paradigma realista. ${ }^{3}$ Desde esta perspectiva, la inseguridad pasa por la violencia o la amenaza real de un ataque violento; la seguridad -aumentada o disminuida- estará en función de la capacidad del Estado para impedir el ataque o eliminarlo ${ }^{4}$ para sobrevivir. Por eso, distraerse de tal ob-

2 Para un análisis más exhaustivo del término glocal, véase: Victor Roudometof. Glocalization. A critical introduction, (New York: Routledge, 2016).

3 Richard Ned Lebow, "Introduction", en Max Weber and International Relations, Richard Ned Lebow (ed.), (Cambridge: Cambridge University Press, 2017), 1.

4 La idea original viene de Wolfers, Arnold, "Discord and Collaboration, citado en Laura Neack, Elusive Security: States first, people last, Rowman \& Littlefield Publishers, Inc., (Estados Unidos: Rowman \&Littlefield Publishers, 2007), 3. 
jetivo no sólo es incorrecto sino peligroso al desviar la atención a todo aquello que sí es considerado crucial para la seguridad nacional. La policía, las agencias de inteligencia y las fuerzas de defensa tienen el objetivo común de preservar el orden, la estabilidad y el buen funcionamiento del Estado. Este andamiaje institucional y su estabilidad 5 son cardinales para alcanzar una seguridad interior.

Tradicionalmente la seguridad nacional ha buscado lograr alcanzar la ausencia de amenazas a los valores de un Estado. Protegemos lo que valoramos. Históricamente, la seguridad misma ha sido considerada un valor esencial y el fin último de la conducta de los Estados. ${ }^{6}$ Una noción clásica de la seguridad, a mediados del siglo pasado, ya la desagregaba en un sentido objetivo y subjetivo.

Arnold Wolfers (en su obra National Security as an Ambiguous Symbol, 1952), afirmaba que la seguridad, en un sentido objetivo, medía la ausencia de amenazas a valores adquiridos, mientras que en un sentido subjetivo medía la ausencia del miedo de que tales valores fueran atacados. La formulación de Wolfers -para quien no era posible medir objetivamente la seguridadmostraba con claridad la tensión entre una concepción objetiva de la seguridad (ausencia/presencia de amenazas concretas) y una subjetiva (la percepción de sentirse amenazado, o no). ${ }^{7}$ Hoy en día aún permea, en las instituciones de seguridad en México, una noción de que la seguridad nacional es totalmente objetiva y parece que toda la tecnología que se utiliza en la investigación de seguridad nos proveerá de esa objetividad sobre la cual la nación pudiera descansar; pero no es así. Las evaluaciones de qué o quién está amenazado por qué o quién, siguen siendo derivadas de apre-

\footnotetext{
5 Las instituciones de seguridad nacional constantemente están sujetas a periodos de inestabilidad, sea por cambios de gobierno o por el asedio de fuerzas agresivas o corruptoras.

6 Graham Evans and Jeffrey Newnham, Penguin Dictionary of International Relations, (Inglaterra: Security, 1998), http://rezadelavari.com/files/filebank/penguin_ dictionary.pdf

Este análisis es de Barry Buzan and Hansen Lene, The evolution of International Security Studies, (Cambridge: Cambridge University Press, 2010), 32-33.
} 
ciaciones subjetivas y diversas construcciones sociales. Lamentablemente -dice Laura Neack- la concepción dominante de la seguridad nacional ha hecho poco para responder a qué nos referimos con "valores" o "amenazas" de tal manera que nos conduzcan a un Estado o un mundo más seguro. ${ }^{8}$

Sin embargo no hay duda: proteger el Estado (mantener la integridad del gobierno y su régimen, el territorio y la población), su identidad, soberanía y capacidad funcional sigue y seguirá siendo una prioridad, pero no la única. Esta visión clásica, estado-céntrica, militarista, hobbesiana, draconiana y tradicional, en donde los ciudadanos o el medio ambiente son irrelevantes, está experimentando una metamorfosis, especialmente desde el fin de la Guerra Fría, y en México no es la excepción.

Hoy, las definiciones se están expandiendo y cada vez más se acepta -teórica y prácticamente- que le competen a la seguridad nacional los temas que amenacen al Estado, a su población, a su medioambiente, a sus valores, a sus vías de comunicación, a su capacidad funcional, a sus instituciones y a su patrimonio e identidad cultural. De hecho, el Programa para la Seguridad Nacional 2014-2018 nos presenta una visión extendida, una seguridad nacional multidimensional en la que, por ejemplo, las amenazas de carácter medioambiental son clasificadas como relevantes en tanto "riesgos globales" -junto con otros riesgos derivados del aspecto tecnológico, energético y demográfico-. ${ }^{9}$ En el Diario Oficial de la Federación donde se plantea esta concepción multidimensional de la seguridad, innovadoramente desde el gobierno mexicano, se estipula que la dimensión ambiental forma parte, nada más y nada menos, del poder nacional junto con la dimensión militar, diplomática, económica y cultural.

8 Laura Neack, Elusive Security: States first, people last, (Estados Unidos: Rowman \& Littlefield Publishers, Inc., 2007), 3.

9 Diario Oficial de la Federación DOF. Programa para la Seguridad Nacional 2014-2018, Una politica multidimensional para México en el siglo XXI. Diario Oficila de la Federación, http://diariooficial.segob.gob.mx/nota_detalle.php?codigo $=5342824 \&$ fecha $=30 / 04 / 2014$ 
Así, el péndulo de la seguridad nacional se está moviendo y oscila entre aproximaciones tradicionales y no-tradicionales; entre visiones limitadas y extendidas; entre el poder duro y el poder suave. Con esto, es válido preguntarse ¿Cómo perciben los mexicanos las amenazas internas o externas? Análisis de opinión pública producidos en México dan cuenta de las percepciones que tienen los mexicanos sobre distintos asuntos mundiales que tocan una dimensión interna y otra dimensión externa de la seguridad. Por ejemplo, en la dimensión doméstica "para el Público y los lideres mexicanos los asuntos mundiales afectan más a México que a ellos mismos. Entre estos asuntos, los más importantes son aquelos más cercanos a su bienestar y la seguridad nacional (crimen y narcotráfico, desastres naturales, crisis económicas y energéticas y cambio climático) que los vinculados con la seguridad internacional (terrorismo internacional, armas nucleares y guerras en otros países) ${ }^{10}{ }^{10}$ En lo que respecta a la dimensión internacional, actualmente existe una percepción que favorece la preferencia por evitar problemas o conflictos caracterizados por una noción tradicional de seguridad como aquella vinculada a la fuerza militar. En vez de funcionar a través de una política exterior con una lógica del poder duro (hard power), se prefiere funcionar a través de una política exterior con una lógica del poder "suave" (soft power): "La mayoría de los mexicanos está de acuerdo con el uso de poder suave (cultura, cooperación internacional, diplomacia y comercio) y en desacuerdo con acciones como el uso de la fuerza militar. Además consideran importante apoyar a las empresas mexicanas en otros países, promover la imagen (positiva) de México en el extranjero y con eso atraer turistas". ${ }^{11}$

Resulta importante esta concepción pacífica de la seguridad en el exterior porque con una proyección "suave" de México en el extranjero que atraiga más turistas o que mejore la percepción hacia los mexicanos que residen en el extranjero -y que mandan sus di-

\footnotetext{
${ }^{10}$ Maldonado, Gerardo et al., Los Mexicanos Ante los Retos del Mundo: Opinión Pública, Lideres y Politica Exterior, Resumen ejecutivo, (México: CIDE, 2018), 12.

11 Ibid.
} 
visas a territorio nacional- se mejora el flujo de divisas extranjeras que ingresan al país (sea por turismo o por remesas) aumentando el empleo interno, dinamizando la economía, e indirectamente redistribuyendo la riqueza; en suma, aumentando la seguridad económica y en parte la seguridad humana de los mexicanos. Dicho de otra forma, a través de la búsqueda del soft power, en vez del hard power, se podrían alcanzar los objetivos más amplios de la seguridad como el de la "libertad de querer" (freedom from want), en vez de la simple "libertad del miedo" (freedom from fear). Esto es un avance en mejorar las dimensiones de la seguridad de los mexicanos a pesar de lo imposible que parezca alcanzar una "libertad de toda amenaza" (freedom from all threat) desde un punto de seguridad nacional.

Impostergable es que, dentro de esa gran matriz que es la "seguridad nacional" de México, la seguridad pública se depure radicalmente y se mejore sustancialmente. ${ }^{12}$ Sin seguridad pública en las calles, en las escuelas, en las universidades, en el sistema de transporte, en las cárceles, en las carreteras, en los bancos, en los sitios turísticos, en los espacios deportivos y en los propios hogares, cualquier aspiración a mejorar la seguridad -del Estado o la población- será ficticia e irrelevante. Las recomendaciones oficiales que hacen algunos países (principalmente Estados Unidos) a

${ }^{12}$ El Consejo Mexicano de Asuntos Internacionales (COMEXI) identifica diez causas que explican la compleja situación actual al interior de México en (in)seguridad pública y las resume de la siguiente manera: La politización en la instrumentación de las políticas de seguridad; la ausencia de una política de Estado en la que converjan los tres poderes; la visión centralista de que la seguridad pública se construye de arriba hacia abajo con escasa participación y compromiso de actores estatales y municipales y de la sociedad; las deficiencias e insuficiencias en el capital humano de las instituciones y altos niveles de corrupción, consecuencia directa de la impunidad en todos los órdenes de gobierno; la debilidad de la política de prevención social de la violencia y el delito, la ausencia de diálogo entre las políticas sociales y las políticas de seguridad y la baja o nula participación ciudadana; las deficiencias en la arquitectura institucional y el déficit en la coordinación interinstitucional entre los distintos órdenes de gobierno; la dificultad para implementar un modelo policial único en contextos locales diversos; la ausencia de claridad respecto al rol de las Fuerzas Armadas en las políticas de seguridad pública y sus consecuencias no deseadas; las deficiencias de los sistemas de inteligencia para la seguridad pública; las deficiencias e insuficiencias en la cooperación internacional. Véase el Resumen Ejecutivo del Consejo Mexicano de Asuntos Internacionales (COMEXI), Una estrategia de seguridad pública para proteger a la ciudadanía, (Ciudad de México: COMEXI, 2018), 5. 
sus ciudadanos de no viajar a algunas localidades en México por la inseguridad pública es una muestra de su repercusión internacional. Sin seguridad pública -por efecto de corrosión institucional, social y política- es muy difícil construir seguridad nacional; y si la seguridad nacional y la seguridad internacional están vinculadas indisolublemente, entonces la seguridad pública, atomizada y desagregada de muchas formas al interior del territorio, es fundamental. Sin seguridad pública, la seguridad nacional implota. ${ }^{13}$

\section{La seguridad internacional}

La seguridad internacional se refiere a aquella que ocurre en el exterior, fuera de la frontera de los Estados. Se presenta tradicionalmente como el objetivo que algunos Estados logran (y otros no tanto) en la selva mundial donde impera la ley del más fuerte en un ambiente de anarquía, es decir, sin un gobierno mundial híper/supra-jerárquico. La única salida es volverse poderoso o aliarse con un poderoso para no ser absorbido/conquistado/sometido por otro Estado. Esta descripción es la de "un mundo de alta política, de cumbres internacionales, de guerra y conflicto; de armas nucleares y otros arsenales militares, de soldados y pacificadores de las Naciones Unidas (ONU); de luchas geopolíticas en que los Estados compiten en un juego de suma cero por el poder y la influencia y, en última instancia, por la supervivencia nacional". ${ }^{14}$

Desde el nivel internacional, poco puede hacer un Estado para impedir que las amenazas lleguen, desde afuera, a sus fronteras. Lo que sí puede hacer es prepararse para aminorarlas, inhibirlas o repelerlas. Hay una sensación de impotencia para los Estados de no poder evitar estar inmersos en una dinámica internacional que los arrastra hacia donde no siempre quieren ir: una inercia internacional. Aquí, las condiciones de inseguridad de un Estado vienen del exterior. Esta visión estructural (neo-realista) de la inseguridad internacional explica las guerras internacionales.

\footnotetext{
${ }^{13}$ La implosión de la seguridad ocurre al romperse hacia adentro con violencia y derrumbarse sobre sí misma. Construir seguridad nacional sin seguridad pública es un sin sentido. ${ }^{14}$ Alexandra Gheciu and William C. Wohlforth, The Oxford Handbook of International Security, (Oxford: Oxford University Press, 2018), 1.
} 
Los Estados, desde esta perspectiva tradicional, están condenados a vivir en la inercia hobbesiana por la incapacidad que tienen de modificar, por sí mismos, la dinámica del temor constante y del peligro de una muerte violenta: ${ }^{15}$ una vida de inseguridad. México tuvo su propia experiencia en 1838-39 y 1862-67 con Francia; en 1846-1848 con Estados Unidos, o durante las dos guerras mundiales del siglo XX: la inseguridad venía del exterior.

Desde el punto de vista de la escuela de pensamiento conocida como Realismo Político tal vez sea sencillo, ontológicamente, descomponer la realidad en tres niveles de análisis: el individual, el estatal y el internacional. Las obras seminales de Kenneth Waltz $\left(1959 ;^{16} 1979^{17}\right)$ argumentan cómo es teórica, metodológica y epistemológicamente viable identificar claramente esos tres niveles de análisis. Para Waltz -y casi todos los neo realistas- es en la dimensión internacional donde se encuentran las causas de la guerra y, por consecuencia, es la dimensión más neurálgica para la inseguridad en cualquier nivel. ${ }^{18}$ Por eso, el papel de la fuerza militar es preponderante en la acción de los Estados, que consiste en la búsqueda/persecución instrumentalmente racional del interés propio. ${ }^{19} \mathrm{El}$ realismo político concibe así una seguridad estado-céntrica, caracterizada por dinámicas de equilibrios de poder identificadas a lo largo de la historia (sistemas unipolares, bipolares y multipolares). Los criterios para alcanzar la seguridad, desde esta perspectiva, vienen impuestos de afuera hacia dentro, de lo internacional a lo doméstico, y no al revés.

Sin embargo, en un espacio muy reducido de tiempo -toda la mitad del siglo XX y lo que va del XXI- la globalización, la in-

\footnotetext{
15 Tomado de la misma descripción de Thomas Hobbes.

${ }^{16}$ Kenneth N. Waltz. Man State and War. A Theoretical Analysis, (New York: Columbia University Press, 1959).

${ }^{17}$ Kenneth N. Waltz. Theory of international politics, (Reading, Mass, Addison Wesley, 1979).

${ }_{18}$ Para otros, las fuentes de inseguridad provienen de realidades más inmediatas, más concretas y menos abstractas (como la Anarquía en Relaciones Internacionales, que es intangible, pero fundamental en el pensamiento realista).
}

${ }^{19}$ Alexandra Gheciu and William C. Wohlforth, The Oxford Handbook of International Security, (Oxford: Oxford University Press, 2018), 7. 
terconexión y la interdependencia se han acelerado y profundizado, de tal manera que es casi imposible para un internacionalista - o cualquier ciudadano observador del mundo- poder identificar claramente a qué nivel pertenece cada fenómeno de la realidad, hoy en día tan compleja. Evidentemente el Estado ya no es el único actor de la seguridad; ahora proliferan las "empresas de seguridad privada, ONG que ofrecen evaluaciones de riesgo o firmas especializadas en seguridad cibernética de las que depende el Estado". ${ }^{20}$ La seguridad internacional ya no se ocupa sólo de la seguridad del Estado como única unidad de análisis, de la lucha de las grandes potencias, de la proliferación nuclear o de la economía de guerra; ahora también abarca la degradación medioambiental y el cambio climático, la seguridad energética, la escases del agua, las amenazas cibernéticas, las representaciones visuales que securitizan imágenes (i. e. Kurt Westergaard del Jyllands-Posten en Dinamarca; Charlie Hebdo, en Francia, etc.), los actores no estatales transnacionales -terroristas, tratantes, narcotraficantes-, los refugiados y las nuevas formas y rutas de migración, o el creciente papel del Sur Global en la política internacional. ${ }^{21}$ Con todo, todavía hay una transición que no termina aún, que va de la seguridad de los Estados a la seguridad de la humanidad. Cuando el Estado se vuelve la amenaza misma a su población la comunidad internacional ya siente una obligación o una responsabilidad de proteger (R2P), relegando nociones obsoletas de soberanía y no intervención. Como afirma Michael Barnett, "la seguridad ha sido humanizada e internacionalizada”. ${ }^{22}$

\section{La seguridad desde el centro turbio y desordenado}

Por mucho tiempo se consideró que los asuntos de los Estados eran o domésticos o internacionales, internos o externos, en blanco y negro, relativamente fácil de distinguirse maniqueamente

\footnotetext{
${ }^{20}$ Ibid, 4 .

${ }^{21}$ Ibid, 5 .

22 Barnett, Michael. "Constructivism”. En: Alexandra Gheciu and William C. Wohlforth, The Oxford Handbook of International Security, (Oxford: Oxford University Press, 2018), 92.
} 
uno de otro. Las fuentes de las amenazas a la seguridad no eran la excepción. Se concebía tradicionalmente a la inseguridad como algo que sucedía fuera de nuestras fronteras y que era un asunto exclusivo de hombres de Estado y de diplomáticos; esa concepción ya no se sostiene. Es tan sofisticada la inseguridad que no podemos dejarla solo en manos de los tomadores de decisiones, diplomáticos y élites militares. ${ }^{23}$

Hoy por hoy, con la globalización y sus lados oscuros, la emergencia de actores no estatales -legales e ilegales que operan a nivel local, nacional y global-, la tecnología usada ilícitamente, la debilidad de los Estados como garantes de seguridad, la corrupción multinivel y omnipresente, la crisis medioambiental con su efecto multiplicador de amenazas (threat multiplier), la desinformación, entre otros factores, hacen muy difícil identificar la naturaleza interior o exterior de la inseguridad. Los problemas de la realidad, en particular las amenazas a la seguridad, tienen causas y consecuencias que pueden originarse o manifestarse, respectivamente, dentro o fuera de las fronteras de los Estados. Actualmente, el origen y destino de las amenazas no está en un claro contraste de blanco y negro, es más bien un conjunto de grises, una turbiedad. $\mathrm{Si}$ en un extremo tenemos a los aspectos internos y en otro a los aspectos externos, en medio de éstos hay un centro poco transparente, sin claridad, azaroso, confuso, revuelto, enredado, dudoso: un centro turbio y desordenado de la inseguridad.

Esta turbiedad de los origenes de la inseguridad fue en aumento a medida que el contexto mundial se iba transformando, complejizando y globalizando. En el siglo XX, durante la Primera y Segunda Guerra Mundial, los países se preocupaban de cómo la inseguridad internacional podía afectarlos en su situación interna. La dinámica internacional marcaba la pauta. Posteriormente, después del fin de la Guerra Fría los países comenzaron a volver a mirar hacia dentro, fuera de la lógica de amenazas externas provocadas por una bipolaridad que podía derivar en una catástrofe nu-

${ }^{23}$ Christopher S. Browning. International Security. A Very Short Introduction, (New York: Oxford University Press, 2013), 1 
clear. ${ }^{24}$ Había entonces aires de que la democracia, la economía de mercado, la cooperación internacional y las instituciones intergubernamentales marcarían el inicio de una etapa histórica de paz y comercio (un fin de la historia para Francis Fukuyama). Los observadores adivinaban una especie de transición de la guerra tradicional a -si acaso- la guerra comercial. Una década (1991-2001) de ilusión y aparente unipolaridad.

El 11 de septiembre de 2001 (11/S) nos demostró que el mundo no sería tan sencillo y nos trajo de vuelta a su ultra-complejidad. El ataque terrorista a Estados Unidos (Estados Unidos) imbuyó una dinámica distinta y más sofisticada (y confusa) sobre las amenazas externas para los países, en especial para aquellos que se sumaban a la orientación de la política exterior de Estados Unidos No obstante, el terrorismo no representó la misma amenaza para todos los Estados. Eso permitió, en parte, que las visiones alternativas y críticas de la seguridad -que se notaron más después de la Guerra Fría y que privilegiaron la seguridad humana, la seguridad medioambiental, la seguridad económica vinculada al desarrollo, y la seguridad desde los temas de género- continuaran floreciendo. Comenzaron a caminar y competir juntas, más claramente y desde entonces, dos formas de ver la seguridad, la tradicional y la alternativa/crítica. Se privilegió la dimensión interna o externa al depender significativamente de cómo se concebía la seguridad. Éste es un acertijo no resuelto, no hay consensos en la definición de seguridad ni en el origen de las amenazas que dicte una receta de cómo garantizar la seguridad de todos, en todos los sentidos, de todas las amenazas.

Una de las ventajas que da el ejercicio comparativo es la riqueza de los contrastes. No podríamos saber del valor de la seguridad interna para la seguridad internacional sin comparar las dimensiones domésticas e internacionales simultáneamente. Lo mismo a la inversa. No podríamos conocer el valor de la seguridad internacional para la seguridad al interior de un país hasta que no

${ }^{24}$ Durante la Guerra Fría sobraban razones para mantener un ojo -o una de las caras de Janus - en la esfera externa, por el nivel de los peligros provenientes del exterior. 
atestiguamos los efectos de problemas internacionales en las condiciones locales de las poblaciones.

Incluso teóricamente, en Relaciones Internacionales, algunas perspectivas ponen su foco en lo interno, otras en lo externo y otras en ambos. ${ }^{25}$ Una visión al estilo del dios Janus es más que nunca necesaria y obligada: una cara viendo el desenvolvimiento de la realidad interna y otra el de la externa. Hacerlo es vital: La inestabilidad o rebelión interna de un país puede afectar toda una región. Los casos recientes de Siria, Venezuela o Bolivia son emblemáticos. Pero veamos cómo una visión janusina es útil al analizar diversas amenazas actuales a la seguridad: las pandemias, el Crimen Transnacional Organizado vinculado al narcotráfico, la migración y la posible fusión entre Terrorismo y Crimen Organizado.

\section{Pandemias}

Una pandemia (o la propagación mundial de una nueva enferme$\mathrm{dad})^{26}$ puede iniciarse en un territorio específico y extenderse por el mundo; las fronteras y divisiones políticas son irrelevantes. Las consecuencias transnacionales de las pestes en diversas regiones, en tanto enfermedades infectocontagiosas, han sido históricas. De la viruela, se estima que ha acabado con la vida de 300 millones de personas a lo largo de la historia. La peste negra en el siglo XIV mató a decenas de millones de personas en Europa, Asia y el Norte de África. El VIH SIDA dejó una importante huella desde la década de 1980 y prácticamente ha tenido un alcance global. Estas y otras pandemias nos mostraron que la naturaleza de

\footnotetext{
${ }^{25}$ En los estudios de seguridad internacional de Barry Buzan y Lene Hansen esas perspectivas se encuentran claramente clasificadas: aquellas que privilegian la dimensión externa de la seguridad son los estudios estratégicos, el realismo, el constructivismo convencional y el crítico (en el sentido de construcción de colectividades que confronten amenazas comunes). La perspectiva que privilegia la seguridad interna es la de la seguridad humana; y aquellas que privilegian ambas son post- estructuralismo, post-colonialismo, investigación sobre la paz, la escuela feminista, la escuela crítica y la escuela de Copenhague. Ver: Barry Buzan, Barry and Lene Hansen. The evolution of International Security Studies, (Cambridge: Cambridge University Press, 2010). 38 (Tabla 2.2 ISS perspectives in relation to the five questions).

${ }^{26}$ OMS. ¿Qué es una Pandemia? Organización Mundial de la Salud, http://www. who.int/csr/disease/swineflu/frequently_asked_questions/pandemic/es/.
} 
su amenaza exige un análisis más allá de la ya de por sí compleja seguridad nacional, precisamente por el alcance de su ubicuidad. El centro turbio y desordenado de las pandemias para determinar su origen y destino como amenaza es particular. Por ejemplo, el virus A (H1N1), que llegó a México en 2009, resultó ser -al momento de estudiar genéticamente la evolución histórica del virusque tenía origen estadounidense, europeo y asiático desde $1998 .^{27}$ A esta gripe porcina se le atribuyó haber provocado al menos 16 mil defunciones, haber tenido primero presencia en 74 países y territorios (junio 2009) y en la mayoría de los países del mundo después (febrero de 2010), ${ }^{28}$ haber provocado una significativa caída del Producto Interno Bruto (PIB) en la economía mexicana de 2009 y, por si fuera poco, haberle costado una percepción negativa a México en el exterior por creerse que ahí se había originado.

No obstante lo anterior, ninguna de las generaciones de seres humanos que actualmente habitan el planeta Tierra había experimentado una amenaza pandémica tan global y local; tan internacional y nacional, como la que ha dejado la Corona Virus Disease de diciembre de 2019, conocida como COVID-19. Seres humanos, comunidades, Estados y sus respectivos gobiernos, instituciones y la ciencia misma fueron abruptamente rebasados por el nuevo virus SARS-CoV-2. Este es un prominente ejemplo de cómo el origen de una pandemia que apareció en una ciudad (Wuhan, China) puede escalar literalmente a nivel planetario diseminando condiciones de inseguridad en poco tiempo por toda la orbe. Para dimensionar un poco el multi-nivel de amenaza que representa la pandemia del nuevo Coronavirus, podríamos decir, por lo menos, que: la salud de la humanidad en su conjunto se degradó; la cotidianidad de los seres humanos se alteró; la concientización sobre nuestra vulnerabilidad aumentó; nuestra comprensión de la globalización se profundizó; una severa recesión

${ }^{27}$ Comisión Europea, Un estudio aclara el origen del H1N1, CORDIS, Comisión Europea, https://cordis.europa.eu/news/rcn/30832_es.html.

${ }^{28}$ OMS, ¿Qué es el virus gripal A (H1N1) 2009 pandémico? Organización Mundial de la Salud, http://www.who.int/csr/disease/swineflu/frequently_asked_questions/ about_disease/es/. 
económica se gestó; el desempleo aumentó; el precio del petróleo se volatilizó; el peso mexicano frente al dólar cayó; el crimen organizado se diversificó; y la fragilidad del régimen internacional de la salud se evidenció -sólo por mencionar algunos aspectos-.

Para inicios de junio del 2020 el mundo había alcanzado los 6.5 millones contagios y las 382 mil muertes; de esos casos México sumaba más de 97,000 contagios y 10,700 muertes. Una vez diseminado este virus, el centro turbio y desordenado de las fuentes de inseguridad se reflejaba en una reinante incertidumbre: los origenes de las amenazas por contagio (y sus múltiples consecuencias políticas, sociales, económicas, jurídicas, ambientales y energéticas) venían tanto del exterior como del interior de los Estados.

\section{Crimen Transnacional Organizado}

El Crimen Transnacional Organizado (CTO) en lo relacionado a la venta, producción y distribución de drogas ilícitas es otro ejemplo que exige este análisis janusino bifocal. En el caso de México, la dinámica bidireccional y binacional-regional de la violencia con el tráfico de drogas da muestra de la des-territorialización de este problema en América del Norte: tanto el tráfico de drogas de México a Estados Unidos (y la debilidad institucional mexicana que lo permite) como el flujo inverso de armas de alto poder y grandes cantidades de dinero de Estados Unidos a México movilizan un negocio ilícito transnacional de altísimo valor económico pero también de un altísimo costo humano en términos de vidas de personas caídas con profunda y brutal violencia. Como afirma Finckenauer y Albanese, el CTO que opera en México se ha transformado en grupos poli-droga (heroína, metanfetamina, mariguana y cocaína) y en poli-criminales (secuestro, asesinato por contrato, robo de autos, prostitución, extorsión, lavado de dinero y tráfico humano); y mientras que los principales grupos en México son centralmente organizados, sus redes de distribución en Estados Unidos y Canadá están más fragmentados. ${ }^{29}$ La diná-

${ }^{29}$ James O. Finckenauer and Jay Albanese. "Transnational Organized Crime in North America. Transnational Organized Crime. An Overview from Six Continents, en 
mica localmente agresiva del crimen organizado responde directa e indirectamente a la lógica de la economía política internacional del narcotráfico. El centro turbio y desordenado del narcotráfico mexicano radica en lo transnacional de dicha dinámica: sus consumidores están en Estados Unidos principalmente y en Canadá en menor medida; la cocaína viene de Colombia, los precursores químicos para la metanfetamina provienen de varios países, el dinero se lava en el Caribe y algunos países de Latinoamérica ${ }^{30}$ y las peleas por las lucrativas ganancias del negocio van dejando muertos en el territorio de México (principalmente en zonas donde el producto va aumentando de valor de sur a norte).

La seguridad internacional y doméstica (interméstica) de estos problemas se alcanzaría tomando en cuenta los factores internacionales y domésticos simultáneamente, profundamente interconectados: ${ }^{31}$ la violencia y el poder del crimen organizado en México no se puede entender ni explicar sin el gigantesco mercado transnacional de drogas que los financia (nivel internacional) o sin la debilidad de las instituciones al interior del país que genera un débil estado de derecho y una realidad de impunidad (nivel doméstico).

Emblemático es el caso de la desaparición de los 43 estudiantes de Ayotzinapa, Guerrero, que aunque parezca muy local el problema -a nivel municipal- también está conectado a la lógica internacional: en un primer nivel regional y binacional, lo local se conecta con lo internacional por el corredor de tráfico de he-

Reichel, Philip y Jay Albanese (eds.). (Estados Unidos: Sage, 2014), 45.

${ }^{30}$ Ibid, 46.

${ }^{31}$ Cuando reflexionamos sobre la percepción de que el crimen organizado viene de afuera, de algún lugar alejado de nuestro entorno, nos damos cuenta que "lo internacional" en realidad no está tan alejado como parece: uno de los epicentros transnacionales de trata de blancas es Tenancingo, Tlaxcala, a dos horas en auto de la sede del Gobierno Federal en la Ciudad de México. El orígen de la ecuación de esa criminalidad transnacional (con conexiones en Los Ángeles, Phoenix, Dallas, Atlanta, Miami y Nueva York) está en casa y muy cerca. La Organización Internacional del Trabajo indica que "Los beneficios anuales promedio provenientes únicamente de la trata de personas se estiman en 32,000 millones de dólares". Beate Andrees and Aurélie Hauchère. El trabajo Forzoso y la trata de Personas: Manual para los inspectores del trabajo, (Ginebra: Programa Especial de Acción para Combatir el Trabajo Forzoso, OIT, 2009). 
roína de Guerrero a Chicago, de Iguala a Illinois, con la complicidad del Estado. En un segundo nivel, el global, hipotéticamente no es invalido conjeturar que sin el consumo de heroína internacionalmente y las variaciones de producción en Afganistán, México no tendría estos efectos indirectos en el tráfico subnacional, por lo que no es tan errático pensar que el consumo global de heroína puede manifestarse de la manera más indirecta, atroz y local como en este caso particular. ${ }^{32}$

Adicionalmente a la visión janusina (interna y externa) para entender y atender el tema del CTO, igualmente la solución radicará en la descriminalización y legalización de algunas drogas con un énfasis en el enfoque de salud, lo que a su vez irá transformando la naturaleza de la amenaza que presenta y representa actualmente el narcotráfico. Las tendencias hacia la legalización de la mariguana son más visibles que las de otras sustancias; no obstante, el Estado mexicano ha dejado ver que hay una tendencia hacia flexibilizar los enfoques punitivos y draconianos del actual régimen internacional de las drogas. ${ }^{33}$

\section{Migración}

Por su parte, la seguridad en la migración internacional es otro tema evidentemente janusino, tanto por los migrantes que salen como por los que entran a través de las fronteras propias y ajenas. Éste es un tema muy recurrido y analizado. Para usar una ramificación del tema migratorio aún más emblemática, tenemos a aquella migración -local o transnacional- por causas am-

\footnotetext{
32 Sobre una elaboración más exhaustiva sobre el cuarto nivel de análisis (el municipal) en este caso, véase: Jorge Rebolledo Flores, Drogas, Politica y Contexto: La Formulación De La Politica Antidrogas en México, Estados Unidos: Tesis Doctoral, Univesity of Miami, 2017).

${ }^{33}$ En su momento, el Secretario de la Defensa Nacional de México se manifestó a favor de legalizar el cultivo de la amapola con fines medicinales como una salida al problema de la violencia. Esa declaración fue hecha en el contexto de la apertura del 41 Batallón de Infantería en el municipio de Teloloapan, en la región norte del estado de Guerrero, en donde la inseguridad ha aumentado (por ejemplo, en las comunidades del municipio de Pilcaya y Ahualulco en Tetipac). Véase: "Cienfuegos, a favor de legalizar el cultivo de amapola”, El Universal, 05 de octubre, 2018. http://www.eluniversal.com.mx/ nacion/cienfuegos-favor-de-legalizar-el-cultivo-de-amapola.
} 
bientales. La migración climática de México a Estados Unidos (Tlaxcala, Puebla y Oaxaca) ${ }^{34}$ de los campesinos que padecieron la desertificación en sus tierras por un efecto del calentamiento global nos deja un problema de niveles de análisis al intentar identificar claramente causas y consecuencias. Determinar causalidad en este caso no es fácil ya que para muchos es seriamente debatible la correlación y eventual relación causal entre cambio climático y migración; el centro turbio y desordenado aquí es evidente. La cadena "calentamiento global-desertificación-migración”, que causa inseguridad humana, teóricamente va de lo global, a lo local y de ahí -con la migración- a lo transnacional. ${ }^{35}$ Específicamente, la migración climática de México a Estados Unidos no se puede entender sin el calentamiento global (nivel internacional/global) ni la desertificación de la tierra y falta de empleo (nivel doméstico/local).

Más allá del tema ambiental, la migración México-Estados Unidos ha escalado a tal nivel, que el Estado mexicano ha institucionalizado el esfuerzo - aún insuficiente- de proveer de seguridad a los migrantes mexicanos que viven en suelo estadounidense. De hecho, "México cuenta con la red consular más grande que tenga o haya tenido un país en otro, sumando 50 consulados en un solo país, Estados Unidos, [para] dar atención y ofrecer pro-

\footnotetext{
${ }^{34}$ En general, varios trabajos pueden ser consultados al respecto: Silvia Herrera Cortés and Bulmaro Juárez Hernández. "Pronóstico de Variables Climatológicas del Estado de Tlaxcala”, Modelación Matemática. Ingeniería, Biología y Ciencias Sociales, en Silvia Reyes Mora y Luna Olivera (coords). (México: Universidad Tecnológica de la Mixteca, 2016), 105-111. Sobre la relación migración y medio ambiente, ver: Adolfo Albo and Juan Luis Ordaz Díaz, "Migración y Cambio Climático. El caso mexicano”, Documento de Trabajo 11 No. 27, (2011). Disponible en: https://www.bbvaresearch.com/ KETD/fbin/mult/WP_1127_Mexico_tcm346-267325.pdf. (Consultado el 2 de junio, 2020).

Sobre migración de norte a sur: Consejo Nacional de Población, Regiones de origen y destino de la migración México-Estados Unidos, CONAPO, http://www.conapo.gob. $\mathrm{mx} /$ work/models/CONAPO/intensidad_migratoria/pdf/Regiones.pdf (Consultado el 2 de junio, 2020).

35 Sobre la relación entre medio ambiente y migración véase la tesis de investigación: Lucero de Jesús Ruíz Guzmán. La Migración indocumentada de México a Estados Unidos de América como consecuencia de la desertificación por el cambio climático (20052015), Alberto Lozano Vázquez (dir.) (Oaxaca: Universidad del Mar, 2017).
} 
tección a las más de 36 millones de personas de origen mexicano viviendo en ese país, de las cuales aproximadamente 12 millones nacieron en México, 12 millones son de segunda generación y los 12 millones restantes son de tercera o más generaciones. ${ }^{36}$ Aparte de la seguridad humana ahí implicada, la seguridad económica que dota a México la masiva cantidad de remesas que esos mismos migrantes mandan en dólares es imprescindible en cualquier análisis del vínculo general seguridad-migración.

\section{Fusión entre Terrorismo y Crimen Organizado}

Finalmente, la combinación entre terrorismo y crimen organizado viene a complejizar más la tarea de distinguir lo doméstico de lo internacional en la seguridad, exigiendo un análisis más desdoblado. Aunque México no está exento de ataques terroristas, podemos afirmar que, en lo general y en sentido conceptualmente estricto, éste aún no es un país que se ubique como fuente o destino de ataques de esta naturaleza.

La frontera con Estados Unidos ha sido un factor que se ha considerado importante por la posible penetración de terroristas a suelo estadounidense dada la asimétrica porosidad a lo largo de sus 3,142 km. de longitud. Por su alta relevancia y complejidad, el terrorismo es uno de esos fenómenos más difíciles de identificar en tanto fuente de amenaza doméstica o internacional. Dado que los terroristas buscan fines políticos, al factor de la nacionalidad o del territorio se impone el de la ideología. Cualquier ciudadano sin importar su nacionalidad puede convertirse en seguidor de una ideología terrorista, dotando de un sentido de ubicuidad efectiva a sus reclutadores.

En 2011, criminales mexicanos estaban supuestamente involucrados en un atentado terrorista que tendría lugar en Estados Unidos Aparentemente, dos distintos tipos de actores no-estatales globales -terroristas y criminales organizados- se coordi

\footnotetext{
${ }^{36}$ Susan Gzesh and Jorge Schiavón. "La protección consular mexicana ante la administración Trump: recomendaciones de acción inmediata”. Documentos de política migratoria. (México: Centro de Investigación y Docencia Económicas, CIDE MIG, abril de 2018), 6.
} 
narían para un objetivo terrorista. Funcionarios iraníes fueron acusados en 2011 de conspirar para asesinar al embajador de Arabia Saudita en Estados Unidos, Adel al-Jubeir. El argumento que entonces salió a la prensa ${ }^{37}$ es que a través de un hombre estadounidense de origen iraní, Mansour J. Arbabsiar, los terroristas intentaron contratar asesinos de un cártel mexicano de la droga -Los Zetas- por \$1.5 millones de dólares. Los planes nunca progresaron porque estaban tratando con un informante de la DEA. Los funcionarios iraníes negaron obviamente la acusación. La contextual convergencia entre crimen organizado (narcotraficantes) y terrorismo abre la posibilidad de una relación simbiótica entre dos naturalezas distintas de criminalidad.

El centro turbio y desordenado de la inseguridad tal vez no podría ser peor por vincular a dos amenazas globales con manifestaciones locales: terrorismo y crimen organizado. Desde la década de 1990, estos vínculos se han vuelto más frecuentes. Los grupos terroristas a menudo dependen del CTO para financiar y llevar a cabo sus operaciones. Existe una creciente preocupación por las conexiones entre los terroristas y los grupos criminales transnacionales, pero en la mayoría de los casos son matrimonios de conveniencia episódicos. ${ }^{38}$ Como quiera que sea, esa potencial vinculación debe considerarse seriamente por la letalidad de sus métodos y por la impredictibilidad de su violencia para alcanzar sus fines políticos. ${ }^{39}$ Hasta ahora, México no ha sido percibido como una fuente comprobada de maridaje entre terrorismo y CTO. Un cambio hacia una percepción negativa tendría cruciales repercusiones en la política exterior de Estados Unidos hacia México. ${ }^{40}$

37 “Iranians Accused of a Plot to Kill Saudis' U.S. Envoy", The New York Times, 11 de octubre, 2011. Disponible en: http:/www.nytimes.com/2011/10/12/us/us-accuses-iranians-of-plotting-to-kill-saudi-envoy.html?pagewanted $=$ all \&_r $=0$

${ }^{38}$ Lutz and Lutz, “Terrorism”, en Alan Collins, Contemporary Security Studies, (Nueva York: Oxford University Press, 2010), 339-341.

39 Snow lo define originalmente así: "Terrorism is the use of unpredictable violence to achieve political ends". Donald Snow, National Security for a New Era, (Estados Unidos: Pearson, 2004).

${ }^{40}$ El papel que juegan las percepciones y las ideas en la seguridad es crucial, justo porque pueden influir en la toma de decisiones de política exterior, más allá de la informa- 
Las pandemias, el Crimen Transnacional Organizado vinculado al narcotráfico, la migración y la posible fusión entre Terrorismo y Crimen Organizado demuestran que su naturaleza transnacional requiere de la cooperación internacional de los Estados dado que rebasan sus respectivas soberanías. En la naturaleza de los problemas externos el Estado encuentra límites en su capacidad de acción y solución. La naturaleza internacional, transnacional o global de estos problemas rebasa sus capacidades de acción política y esto debe ser tomado en cuenta para las decisiones internas. Dicho de otro modo, las decisiones sobre seguridad pueden ser internas, pero deben de considerar las limitaciones estructurales impuestas por la dimensión externa.

\section{Reflexiones Finales}

Con nuestra analogía de Janus en la seguridad - que puede tener muchas aplicaciones metafóricas- el Estado debe cuidar de las dos puertas a las que tiene acceso, adonde llegan las amenazas, una puerta interior y otra exterior. Las fronteras del Estado establecen la diferencia entre el fin de lo doméstico y el inicio de lo internacional. En ese sentido, la seguridad tiene esta dualidad, es interna y es externa. Por eso es que aquí se afirma que la seguridad nacional y la seguridad internacional son dos caras de una sola entidad y por ende permanecen en un vínculo indisoluble. El Estado debe de mirar simultáneamente a ambos lados de la seguridad; enfocarse en uno solo de los lados lo vuelve miope y, por tanto, vulnerable.

Examinamos que en la seguridad hay una tercera zona en la que los fenómenos de inseguridad ocurren y no se trata exclusivamente de la seguridad nacional o de la internacional, sino de un centro turbio y desordenado: entre el nivel interno y externo, do-

ción dura y comprobada que se tenga disponible: "Las administraciones de Clinton y Bush no difirieron sustancialmente en su información sobre Irak. Pero los funcionarios de la administración Bush, y el propio presidente, tenían creencias que diferían sustancialmente de las de sus predecesores, y esas creencias tenían profundos efectos”. En: Emile M. Hafner-Burton et al., "The Behavioral Revolution and International Relations", International Organization, 71, No. S1 (2017): S1-S31, doi: 10.1017/ S0020818316000400. 
méstico e internacional, local y global hay una zona de claroscuros, una area del espectro que no puede distinguirse claramente. Se asemeja a una zona turbia donde no hay claridad en el agua, lo que parece local puede ser internacional y lo que parece internacional puede ser local. No hay claridad sino más bien turbiedad.

Podría pensarse intuitivamente que tanto los tomadores de decisiones como los academicos frecuentemente recurren a este análisis bi-dimensional cuando se trata de seguridad en lo general, sin embargo este vínculo no siempre es tomado en cuenta, lo que implica una observación parcial de la realidad que pretenden abordar y resolver. A los responsables de la seguridad de México conviene recordar esta bi-dimensionalidad en la seguridad, tal vez más vigente que nunca. Como un gobierno no puede resolver absolutamente todo, sino que debe atender lo que urge e importa más, al determinar lo que está en peligro deberá hacerlo poniéndose la máscara del dios Janus, para vigilar las dos dimensiones de la inseguridad.

Por otro lado, no debemos olvidar que el problema (o la amenaza) en concreto y el contexto histórico cuentan mucho para orientar los esfuerzos de alcanzar seguridad. Las implicaciones del contexto del 11/S no son las mismas que las de la COVID-19. Debemos determinar cuáles son las amenazas y para quién. Así como el fin de la Guerra Fría del siglo pasado reviró a los Estados a poner más énfasis en la dimensión interna, una Neo-Guerra-Fría en el siglo XXI entre China y Estados Unidos podría dar más peso a la dimensión internacional de la seguridad respecto su contraparte interna; sería un retorno a privilegiar lo externo en términos de seguridad.

Finalmente, y vista la complejidad de los problemas aquí presentados, podríamos concluir adicionalmente que la investigación científica de la (in)seguridad, nacional y/o internacional, también demanda una doble dimensión (otra cara de Janus): la empírica, por ser la más visible, y la teórica, por dotar de sentido de abstracción a lo que vemos de la inseguridad. Esta división se manifiesta en el tradicional y pocas veces superado debate entre la academia y los tomadores de decisiones; la investigación y la política pública, que suelen no dialogar sino ignorarse mutuamente. 
Los tomadores de decisiones suelen tratar con desprecio la parte teórica (incluso la ven como una pérdida de tiempo) por la urgencia que ciertamente demandan los problemas brutales de la realidad. Sin embargo, es evidente que sin una reflexión abstracta de lo complejo de los problemas que ubique las definiciones, los conceptos, las interconexiones entre los problemas y la dimensión histórico-temporal, no se pasará de soluciones cortoplacistas y de poco alcance. La parte práctica y la parte teórica, deben acercarse y acompañarse lo más posible. Necesitamos una incansable comprensión de la (in)seguridad, que le siga el paso a su realidad cambiante. Nadie desea la inseguridad: ni el Estado, ni la sociedad, ni siquiera los criminales - para sí mismos-. La inseguridad en sí misma es indeseable para cualquier persona o entidad política en cualquier momento, en cualquier circunstancia; por eso debe ser reducida ya que su prolongación, por cierto, va debilitando a la incipiente democracia mexicana. La historia sigue corriendo y los escenarios de inseguridad aumentan en ambas caras del dios Janus: tempus fugit.

\section{Fuentes}

Albo, Adolfo y Juan Luis Ordaz Díaz, "Migración y Cambio Climático. El caso mexicano”, Documento de Trabajo. 11 No. 27 (2011), https://www.bbvaresearch.com/KETD/fbin/mult/WW_1127_ Mexico_tcm346-267325.pdf, (Consulta: 2 de junio, 2020). Andrees, Beate and Hauchère, Aurélie. "El trabajo Forzoso y la trata de Personas: Manual para los inspectores del trabajo", Programa Especial de Acción para Combatir el Trabajo Forzoso, Ginebra: OIT, 2009.

Browning, Christopher S., International Security. A Very Short

Introduction, New York: Oxford University Press, 2013.

Buzan, Barry y Hansen, Lene. The evolution of International Security Studies, Cambridge: Cambridge University Press, 2010. Comisión Europea, "Un estudio aclara el origen del H1N1", CORDIS, https://cordis.europa.eu/news/rcn/30832_es.html (Consultado el 3 de junio, 2020). 
Consejo Mexicano de Asuntos Internacionales (COMEXI), Una estrategia de seguridad pública para proteger a la ciudadania, Ciudad de México: Comexi, 2018.

Consejo Nacional de Población, Regiones de origen y destino de la migración México-Estados Unidos, CONAPO, http://www. conapo.gob.mx/work/models/CONAPO/intensidad_migratoria/pdf/Regiones.pdf. (Consulta: 3 de junio, 2020).

Diario Oficial de la Federación (DOF). Programa para la Seguridad Nacional 2014-2018, "Una política multidimensional para México en el siglo XXI”, http://diariooficial.segob.gob.mx/ nota_detalle.php?codigo $=5342824 \&$ fecha $=30 / 04 / 2014$. (Consulta: 2 de junio, 2020).

Dios Palma, Arturo de. "Cienfuegos, a favor de legalizar el cultivo de amapola", El Universal. 05 de octubre, 2018, http:// www.eluniversal.com.mx/nacion/cienfuegos-favor-de-legalizar-el-cultivo-de-amapola (Consultado el 2 de junio de 2020). Evans, Graham and Newnham, Jeffrey. Penguin Dictionary of International Relations, Inglaterra: Security, 1998, http://rezadelavari.com/files/filebank/penguin_dictionary.pdf. (Consultado el 2 de junio de 2020).

Finckenauer, James O. and Albanese, Jay. "Transnational Organized Crime in North America", en Reichel, Philip y Jay Albanese (eds.), Transnational Organized Crime. An Overview from Six Continents, Estados Unidos: Sage, 2014.

Gheciu, Alexandra and Wohlforth, William C. The Oxford Handbook of International Security, Oxford: Oxford University Press, 2018.

Goldstein, Judith and Keohane, Robert O. (eds.), Ideas and foreign policy: beliefs, institutions, and political change. Ithaca: Cornell University Press, 1993.

Gzesh, Susan y Schiavón, Jorge. La protección consular mexicana ante la administración Trump: recomendaciones de acción inmediata. Documentos de política migratoria. Centro de Investigación y Docencia Económicas, A.C., México: CIDE MIG, abril de 2018. 
Hafner-Burton, Emilie M.; Haggard, Stephan; Lake, David A. and Victor, David G. "The Behavioral Revolution and International Relations", International Organization. 71 No. S1 (2017): S1-S31, doi 10.1017/S0020818316000400.

Herrera Cortés, Silvia and Juárez Hernández, Bulmaro. "Pronóstico de Variables Climatológicas del Estado de Tlaxcala”, en Silvia Reyes Mora y Luna Olivera (coords), Modelación Matemática. Ingenieria, Biología y Ciencias Sociales, 105-111, México: Universidad Tecnológica de la Mixteca, 2016.

Lebow, Richard Ned, "Introduction", en Richard Ned Lebow (ed.), Max Weber and International Relations, Cambridge: Cambridge University Press, 2017.

Lutz and Lutz, "Terrorismo”, en Alan Collins, Contemporary Security Studies, 339-341, New York: Oxford University Press, 2010.

Maldonado, Gerardo et al., Los Mexicanos Ante los Retos del Mundo: Opinión Pública, Lideres y Politica Exterior, resumen ejecutivo, México: CIDE, 2018.

Neack, Laura, Elusive Security: States first, people last, Estados Unidos: Rowman \& Littlefield Publishers, Inc., 2007.

OMS, ¿Qué es el virus gripal A (H1N1) 2009 pandémico? Ginebra: Organización Mundial de la Salud, http://www.who.int/ csr/disease/swineflu/frequently_asked_questions/about_disease/es/. (Consulta: 3 de junio, 2020).

OMS, ¿Qué es una Pandemia?, Ginebra: Organización Mundial de la Salud, http://www.who.int/csr/disease/swineflu/frequently_ asked_questions/pandemic/es/.(Consulta: 3 de junio, 2020).

Rebolledo Flores, Jorge. Drogas, Politica y Contexto: La Formulación De La Politica Antidrogas en México, México: Tesis Doctoral, Univesity of Miami, 2017.

Roudometof, Victor. Glocalization. A critical introduction, New York: Routledge, 2016.

Ruíz Guzmán, Lucero de Jesús. La Migración indocumentada de México a Estados Unidos de América como consecuencia de la desertificación por el cambio climático (2005-2015), Lozano Vázquez, Alberto (dir.), México: Universidad del Mar, 2017. 
Skocpol, Theda, States and Social Revolutions. A Comparative Analysis of France, Russia and China, Cambridge: Cambridge University Press, 1979.

Snow, Donald. National Security for a New Era. Estados Unidos: Pearson, 2004.

The New York Times. "Iranians Accused of a Plot to Kill Saudis' U.S. Envoy", 11 de octubre, 2011. http://www.nytimes. com/2011/10/12/us/us-accuses-iranians-of-plotting-to-kill-saudi-envoy.html?pagewanted=all\&_r $=0$. (Consulta: 3 de junio, 2020).

Waltz, Kenneth N., Man State and War. A Theoretical Analysis. Nueva York: Columbia University Press, 1959.

Waltz, Kenneth N., Theory of international politics, Estados Unidos: Reading, Mass, Addison Wesley, 1979.

Wolfers, Arnold, "Discord and Collaboration", citado en Laura Neack, Elusive Security: States first, people last. Estados Unidos: Rowman \& Littlefield Publishers, Inc., 2007. 
